\title{
AS GEOTECNOLOGIAS NA GEOGRAFIA ACADÊMICA E NA GEOGRAFIA ESCOLAR E SEUS DESDOBRAMENTOS EDUCATIVOS
}

\author{
GEOTECHNOLOGIES IN ACADEMIC GEOGRAPHY AND SCHOOL \\ GEOGRAPHY AND ITS EDUCATIONAL DEPLOYMENT
}

\author{
LAS GEOTECNOLOGÍAS EN LA GEOGRAFÍA ACADÉMICA Y EN LA \\ GEOGRAFÍA ESCOLAR Y SUS DESDOBLAMIENTOS EDUCATIVOS
}

\author{
Valéria Cazetta - Universidade de São Paulo - São Paulo - São Paulo - Brasil \\ vcazetta@usp.br
}

\begin{abstract}
Resumo
0 propósito deste texto é pensar com as linguagens cartográfica e do Sensoriamento Remoto a composição de um campo de forças indissociável do pensamento do espaço e da corporeidade, bem como seus paradoxos. Perspectivados desde uma analítica micropolítica, no registro deleuze-guattariano, elementos da cartografia simbólica como escala, projeção e simbologia foram empregados para operar com os mapas e com as imagens tributárias do Sensoriamento Remoto, objetivando compreender o espaço e a corporeidade de modo multiescalar. Assim, produzimos cruzamentos desde uma analítica micropolítica entre práticas educativas junto a escolares, com idade entre 9 e 10 anos, do ensino fundamental 1 da educação básica, especificamente quarto ano; e estudantes de graduação da Licenciatura em Ciências da Natureza (LCN) da Escola de Artes, Ciências e Humanidades (EACH) - Universidade de São Paulo (USP).

Palavras-chave: Educação geográfica, cartografia, Sensoriamento Remoto, micropolítica.
\end{abstract}

\section{Abstract}

The purpose of this text is to consider the cartographic and remote sensing languages whilst thinking about the composition of a force field that is inseparable from thinking space and corporeity, including its paradoxes. From the perspective of a micropolitical analysis in the deleuzian-guattarian key, elements of symbolic cartography such as scale, projection and symbology are employed to operate with maps and tributary images of remote sensing, aiming to understand space and corporeity in a multi-scale way. Thus, we generated crossovers from a micropolitical perspective between diverse educational practices with elementary school students, between 9 and 10 years of age, from elementary education, 4TH Grade, and students from the Science Teacher Education Program (LCN) at the School of Arts, Sciences, and Humanities (EACH) - São Paulo University (USP) in Brazil. Keywords: Geographical education, cartography, Remote Sensing, micropolitics.

\section{Resumen}

El propósito de este texto es pensar con los lenguajes cartográficos y de la Teledetección espacial la composición de un campo de fuerzas indisociable del pensamiento del espacio y de la corporeidad, así como sus paradojas. Desde una perspectiva analítica micropolítica, en el registro deleuze-guattariano, se emplearon elementos de la cartografía simbólica como escala, proyección y simbología para operar con los mapas e imágenes tributarias de la Detección espacial, con el objetivo de comprender el espacio y la corporeidad de modo multiescalar. Así, producimos cruces desde una analítica micropolítica entre prácticas educativas junto a escolares de la enseñanza primaria de la educación básica, con edad entre 9 y 10 años, y estudiantes de graduación en Ciencias de la Naturaleza (LCN) de la Escuela de Artes, Ciencias y Humanidades (EACH) Universidad de São Paulo (USP).

Palabras clave: Educación geográfica, cartografía, Teledetección espacial, micropolítica. 


\section{Introdução}

O título atribuído ao texto, separando a Geografia escolar da Geografia acadêmica, refere-se apenas a uma estratégia didática, pois concebemos uma imiscuída e implicada na outra. Abordaremos linguagens habitualmente localizadas no campo disciplinar da Geografia, seja acadêmica, seja escolar, como os mapas e as imagens provenientes do Sensoriamento Remoto, a despeito de também permearem o dia a dia de muitos grupos sociais, esgarçando as fronteiras de seus usos, funções e maneiras de pensar, conceber e agir no espaço. O modus operandi representacional dos mapas e das linguagens do Sensoriamento interpelam-nos em várias direções: equivaler o mapa ou a imagem como sendo o próprio espaço geográfico; a perspectiva bidimensional dessas linguagens chapa a rugosidade atinente aos lugares; as experiências corporais que, embrenhadas no espaço, compõem um repertório escalar outro: a força com que as coisas chãs ${ }^{1}$ nos tomam de assalto quando a elas nos reportamos.

Chamaremos o cruzamento dessas três direções de composição micropolítica imamente à corporeidade humana e às coisas com as quais nos ocupamos na peleja ordinária da vida: o corpo e o lugar como forças conectivas na forja de um agenciamento da corporeidade como espaço. Para tanto, operaremos teoricamente com a noção de micropolítica na tentativa de escapar dos dualismos impetrados por muitos cartógrafos e geógrafos na lida com as linguagens, ditas geográficas, que nos atravessam a todos e todas, constituindo parte de nossas linhas de latitude e longitude corpóreas e espaciais. Eis, pois, a primeira parte desse texto à qual devotar-nos-emos. Depois, abordaremos brevemente as concepções de espaço em Doreen Massey e Milton Santos, problematizando a prática da espacialização como sinônimo de distribuição de fenômenos no espaço bidimensional. Essa prática, ratificada desde o advento das imagens oriundas das geotecnologias nos âmbitos da Geografia escolar e da Geografia acadêmica, ao invés de ser operacionalizada com diferentes linguagens umas em relação às outras e em escalas variadas, tornou-se apenas um procedimento para fixar ocorrências e dar a ver fenômenos nas superfícies lisas dos mapas. Daí as paisagens transformaram-se em retratos com o propósito de fixar identidades territoriais aos lugares.

Por fim, são apresentados resultados de um estudo sobre o emprego de fotografias aéreas verticais em contexto escolar, bem como o uso do 
globo virtual giratório, mais conhecido como Google Earth (GE), na formação de professores de ciências - disciplina escolar que também tem no espaço o ancoradouro de suas práticas sociais e discursivas, embora nem sempre reconhecido pelos profissionais dessa área do conhecimento -, na ambiência da graduação em Licenciatura em Ciências da Natureza (LCN) da Escola de Artes, Ciências e Humanidades (EACH)², da Universidade de São Paulo (USP).

\section{Composição micropolítica}

Com escalas de abrangência e pautas distintas, entre novembro de 2015 e maio de 2016, houve dois movimentos de ocupação das escolas no Brasil: um envolvendo o estado de São Paulo e o outro mais amplo, espraiado por 22 estados brasileiros. A cantora Marisa Monte, por ocasião do segundo movimento, promoveu um pequeno show em uma das escolas ocupadas da capital do Rio de Janeiro, asseverando:

[...] Só existe amor na micropolítica. Na macropolítica não tem amor, cheguei a essa conclusão. E assim que a gente vai mudar as coisas. Lá em cima não tem nada construtivo. Está ruindo sozinho, a gente não precisa fazer nada. Vamos tirar o lixo das ruas, plantar as árvores. Cada um fazendo sua parte, descobrindo a micropolítica de dentro de cada um3 (destaques nossos).

Em uma primeira investida, a cantora opõe a micropolítica à macropolítica, no entanto, uma está imiscuída na outra e envolve, sobretudo, a vida desde seu gerenciamento biopolítico, abrangendo políticas públicas nas escalas macro e micro, à manutenção diária dos corpos. Se compreendida como sinônimo de ações nos espaços e lugares, circunscritos à escala do detalhe, a micropolítica perde sua força analítica e pode tornar-se uma armadilha. Os dizeres com identidades não geógrafas, mas, nem por isso, menos geográficos, no sentido de uma analítica que cruza as oposições micro e macro, importam sobremaneira, pois, pelo fato de não estarem aderidos a uma identidade disciplinar, seus ditos e escritos ficam mais porosos pelas passagens que realizam entre as fronteiras disciplinares. Tanto autores geográficos, adjetivados, como os autores geógrafos, substantivados, auxiliar-nos-ão daqui por diante a partir da segunda investida de Marisa Monte, conforme o excerto supracitado. Repitamo-lo: "Cada um fazendo sua parte, descobrindo a micropolítica de 
dentro de cada um”, afinal, entre a escala do mais ínfimo detalhe àquela mais generalizada, há conexões infinitesimais.

A micropolítica refere-se, então, ao cruzamento dos acontecimentos sociais mais amplos com aqueles relativos às coisas chãs

Entre esses dois níveis, não há uma oposição distintiva, que dependa de um princípio lógico de contradição. Parece difícil, mas é preciso simplesmente mudar de lógica. Na física quântica, por exemplo, foi necessário que um dia os físicos admitissem que a matéria é corpuscular e ondulatória, ao mesmo tempo (Guattari; Rolnik, 2013, p. 149).

Embora Gilles Deleuze e Félix Guattari não sejam geógrafos, a produção da dupla francesa apresenta um conjunto teórico vultoso para pensar as coisas adjetivadas como geográficas, pois todas assim o são. A dimensão geográfica seria imanente ao próprio espaço e às corporeidades que a animam. Nesse sentido, o sociólogo português Boaventura de Sousa Santos (2000, p. 197) afirma:

Todos os conceitos com que representamos a realidade e à volta dos quais constituímos as diferentes ciências sociais e suas especializações, a sociedade e o Estado, o indivíduo e a comunidade, a cidade e o campo, as classes sociais e as trajetórias pessoais, a produção e a cultura, o direito e a violência, o regime político e os movimentos sociais, a identidade nacional e o sistema mundial, todos esses conceitos têm uma contextura espacial, física e simbólica, que nos têm escapado pelo facto de os nossos instrumentos analíticos estarem de costas viradas para ela, mas que, vemos agora, é a chave da compreensão das relações sociais de que se tece cada um destes conceitos. Sendo assim, o modo como imaginamos o real espacial pode vir a tornar-se na matriz das referências com que imaginamos todos os demais aspectos da realidade (Santos, 2000, p. 197).

Voltemo-nos, brevemente, para os escritos dos geógrafos Doreen Massey (2008) e Milton Santos (1997); cada um teorizou, à sua maneira, sobre a díade conceitual espaço-tempo e cremos haver conexões entre ambos, pois, da forma como fizeram, resolveram a clássica dicotomia entre Geografia humana e Geografia física. A primeira, ao dizer que o espaço trata-se do encontro de trajetórias humanas e inumanas até agora; e o segundo, ao asseverar que o espaço pode ser lido como um conjunto de fixos e fluxos solidariamente indissociáveis. Ademais, tal teorização contribuiu para pensarmos os mapas como forças interpelativas que, em conexões com outras linguagens imagéticas, como aquelas tributárias do Sensoriamento 
Remoto, desmontam o reducionismo simplificado e superficial de que os mapas seriam a linguagem geográfica por excelência, mesmo porque "as imagens não falam de forma isolada, precisamos colocá-las em relação" (Campos, 2017, p. 269), tarefa à qual nos devotaremos daqui por diante.

As imagens das geotecnologias na Geografia acadêmica e na Geografia escolar

Tanto na Geografia escolar como na Geografia acadêmica, grosso modo, as imagens, especialmente os mapas, têm importância nos discursos dos geógrafos e professores de geografia. Um estudo pode ser considerado mais ou menos geográfico, inclusive, em decorrência do emprego ou não de mapas. No entanto, aquilo que as imagens geográficas apresentam não constitui o espaço geográfico ou os lugares em sua totalidade. Como não rememorar o clássico quadro do pintor belga surrealista René François Ghislain Magritte (21/11/1898-15/08/1967), The treachery of imagens (1929) - "A traição das imagens"?

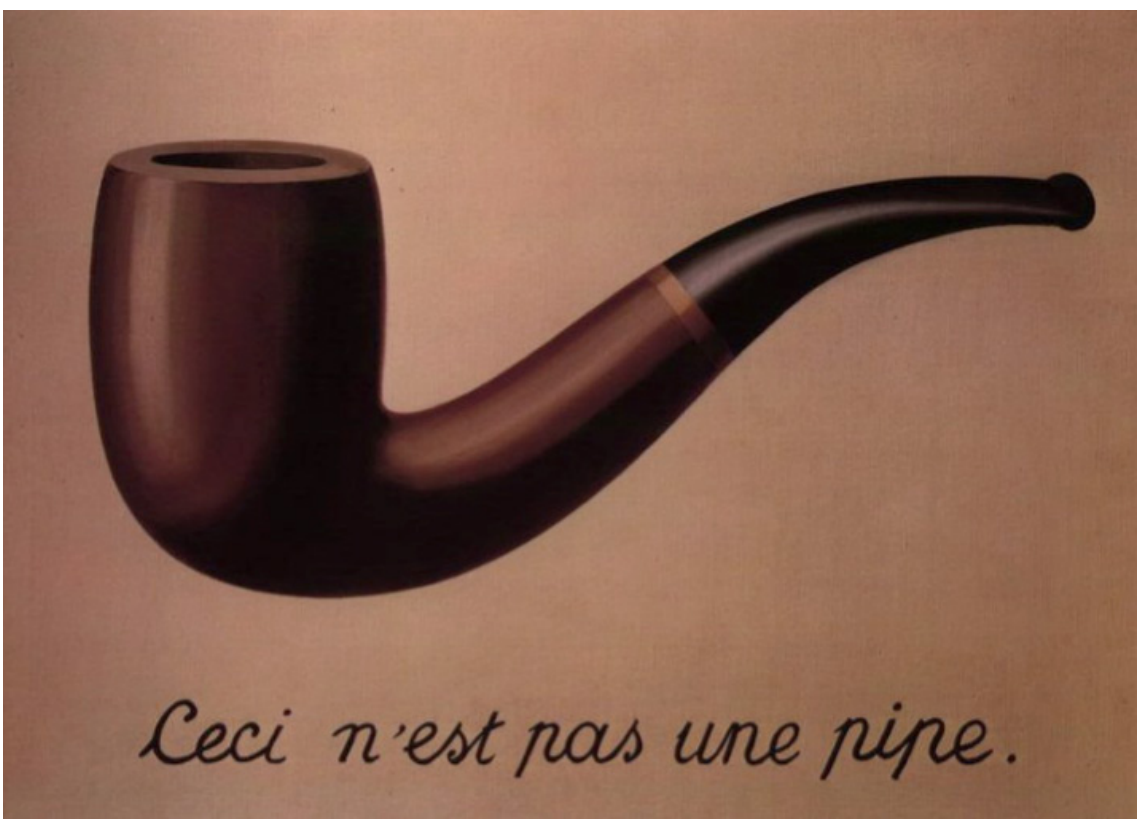

Figura 1 - A traição das imagens, 1929.

Fonte: Disponível em: <https://www.renemagritte.org/the-treachery-of-images.jsp\# prettyPhoto $>$. 
Caberia o mesmo trocadilho com o espaço quando se olha para um mapa? Cremos que sim; olhamos para um mapa qualquer e logo pensamos: Ceci n'est pas l'espace - Isso não é o espaço (Figura 2).

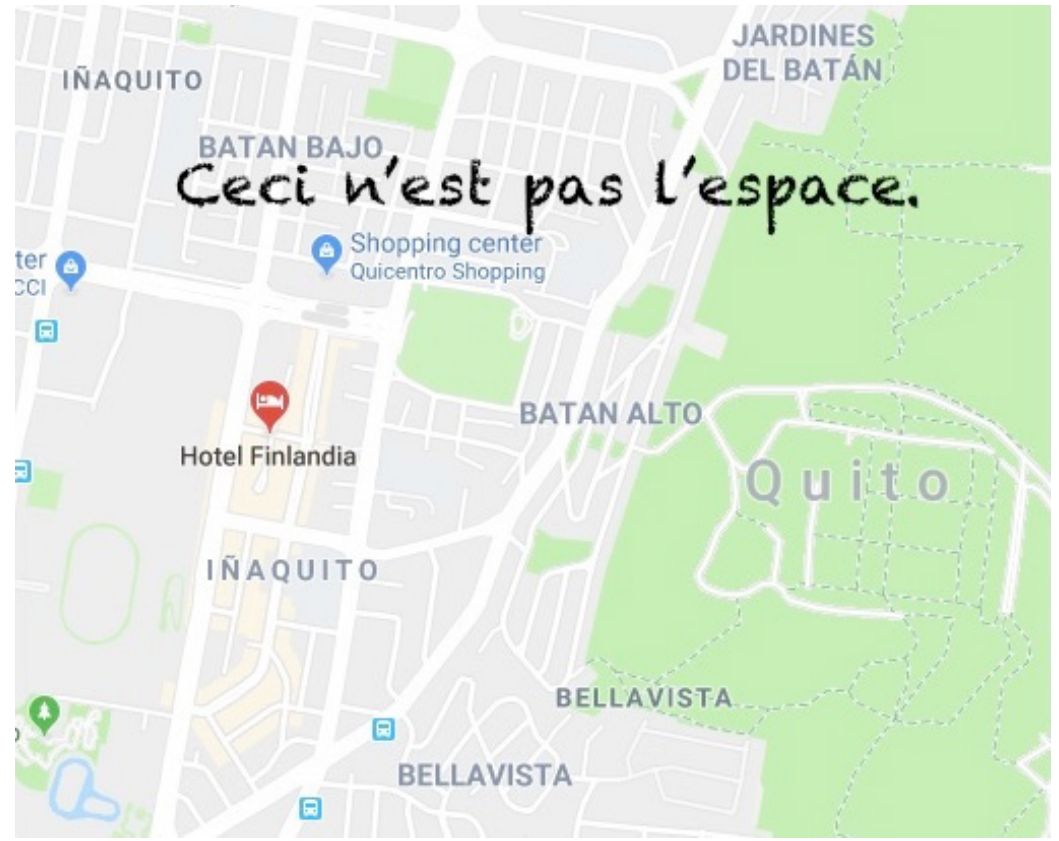

Figura 2 - A traição dos mapas

Fonte: Adaptado da plataforma Google Maps. Acesso em: 12 abr. 2018.

Doreen Massey (2008, p.43) chama a atenção acerca da "associação entre o espacial e a fixação do significado. A representação - certamente a conceituação - foi concebida como espacialização”. Nem todas as visões do alto/de cima são problemáticas, mas o problema surge somente “[...] se começamos a pensar que aquela distância vertical nos traz a verdade [...], que mapas (mapas atuais do tipo ocidental) dão a impressão de que o espaço é uma superfície - que é a esfera de uma completa horizontalidade” (Massey, 2008, p. 160). A concepção de espaço sugerida pelos mapas pode também ser espraiada para as imagens provenientes do Sensoriamento Remoto; as imagens de satélite e as fotografias aéreas verticais disponibilizadas nas plataformas virtuais, como o Google Earth e o Google Maps, estão a ratificar a concepção de que o espaço é uma superfície lisa passível de ser atravessada, conquistada. 
A problemática não reside a favor ou contra os mapas ou dessas linguagens que chapam as rugosidades dos lugares, mas, sim, em como escapar das armadilhas dessas mesmas linguagens ao transformarem tudo em uma superfície lisa, empregando os mesmos elementos que as forjaram, como: escala, projeção e simbologia.

\section{As imagens nas pesquisas geográficas e sua escala de abrangência}

Nos estudos acadêmicos geográficos, as imagens oriundas do Sensoriamento Remoto ${ }^{4}$ têm sido empregadas para subsidiar a produção geográfica e cartográfica sobre diversos temas, desde as "velhas" fotografias aéreas oblíquas e verticais (em preto e branco/P\&B e/ou coloridas) às "recentes" imagens orbitais, vulgo imagens de satélite, e imagens de radar. As aspas empregadas nos referidos adjetivos é justamente para dizer que tanto as fotografias aéreas como as imagens orbitais coexistem. Se, atualmente, há um uso massificado, principalmente no contexto acadêmico e científico, das imagens orbitais, não é porque estas sejam melhores do que as fotografias aéreas verticais, mas sim porque as vantagens apresentadas no processo de obtenção das primeiras, como periodicidade, resoluções espacial ${ }^{5}$ e radiométrica ${ }^{6} \mathrm{e}$ o armazenamento de dados/informações sobre a superfície terrestre, tornaram mais eficaz a produção desse tipo de linguagem do ponto de vista da relação custo e benefício. Como empreender um levantamento aerofotogramétrico é dispendioso, a vantagem das imagens orbitais em relação às fotografias aéreas verticais consiste na obtenção de "informações temporais para atualizações e prognósticos de uma mesma região geográfica com periodicidade de até quatro dias a um custo aproximado de $\mathrm{R} \$ 55,00$ a R\$ 180,00 o quilômetro quadrado" (Assis, 2001, p.15) e com uma resolução espacial cada vez mais detalhada, antes possível somente com as fotografias aéreas verticais.

É fato que as geotecnologias, incluindo o Sensoriamento Remoto, a Cartografia Digital, o Sistema de Posicionamento Global (GPS) e o Sistema de Informações Geográficas (SIG), "fazem parte da tendência de construção de uma infraestrutura voltada para aquisição, processamento e análise de informações sobre o espaço geográfico que busca racionalizar o processo de tomada de decisão" (Matias, 2005, p. 8887). Entretanto, "é preciso estar atento para o verdadeiro significado dessas tecnologias no 
âmbito das ciências geográficas" (Ferreira; Matias, 2011, p. 3) no sentido de "fortalecer as concepções geográficas, já que não é a utilização do SIG que aperfeiçoará as novas gerações de geógrafos, mas os usuários de SIG que irão se aprimorar ao aprofundar o conhecimento da Geografia” (Ferreira; Matias, 2011, p. 10). Geotecnologias, como o Sensoriamento Remoto, têm possibilitado a espacialização de fenômenos geográficos, em diferentes escalas, proporcionando

[...] uma visão de conjunto multitemporal de extensas áreas da superfície terrestre. Esta visão sinóptica do meio ambiente ou da paisagem possibilita estudos regionais e integrados, envolvendo vários campos do conhecimento. Elas mostram os ambientes e a sua transformação, destacam os impactos causados por fenômenos naturais como as inundações e a erosão do solo (frequentemente agravados pela intervenção do homem) e antrópicos, como os desmatamentos, as queimadas, a expansão urbana, ou outras alterações do uso e da ocupação da terra (Florenzano, 2005, p. 24).

Ferreira e Matias (2011), na esteira de Gilberto Câmara e outros autores, afirmam que, apesar dos avanços empreendidos pelos estudiosos nas duas últimas décadas, as geotecnologias "ainda estão longe de dar o suporte adequado às diferentes concepções de espaço geográfico” (p.3), porque a tecnologia de SIG, por exemplo,

[...] resolveu apenas os problemas simples de representação computacional. Os sistemas atuais são intensamente baseados numa lógica "cartográfica", exigindo sempre a construção de "mapas computacionais", tarefa custosa e nem sempre adequada ao entendimento do problema em estudo (Ferreira; Matias, 2011, p. 3).

Nesse sentido, a hipótese defendida é de que as imagens geográficas produzidas no âmbito das geotecnologias continuam a ratificar uma cosmologia espacial "como nas viagens de descobertas [...]. Portanto, esse modo de conceber o espaço pode assim, facilmente, nos levar a conceber outros lugares, povos, culturas, simplesmente como um fenômeno 'sobre' essa superfície” (Massey, 2008, p.22-23).

As imagens no contexto da Geografia escolar e sua escala de abrangência

Concernente a obras educativas geográficas voltadas para o contexto escolar, os mapas constituíram-se, ao longo do estabelecimento da 
disciplina escolar de Geografia, uma de suas principais linguagens para apresentar o espaço geográfico em escalas generalizadas. A partir do final da década de 1990, essas obras incorporaram também as linguagens do Sensoriamento Remoto, integradas aos livros didáticos, atlas geográficos e atlas municipais e escolares; estes últimos publicados no Brasil em fins da década de 1990. Nos atlas geográficos, as imagens do Sensoriamento Remoto, especialmente imagens orbitais de alta resolução espaciais usadas pela plataforma Google Earth, foram inseridas para apresentar escalas mais amplas do território nacional, ao contrário de seu emprego nos atlas municipais e escolares, aos quais foram incorporadas para apresentar o lugar onde se vive em escalas mais pormenorizadas. Embora esses dois tipos de atlas sejam feitos para atender crianças e adolescentes em contexto escolar, ambos lidam com escalas espaciais diferenciadas implicando, possivelmente, ações corporais e pensamentos espaciais também distintos. Não se trata de advogar em prol de um modelo ideal de atlas com imagens mais ou menos generalizadas, mas usá-los apresentando suas diferenças e limitações, porque pensar em várias escalas é um dos raciocínios geográficos imprescindíveis para agir no espaço e no corpo.

A quantidade de imagens do Sensoriamento Remoto cresceu sobremaneira nas publicações de atlas geográficos na década de 1990, além de sua profusão nos livros didáticos de Geografia (Cazetta, 2011; 2012), mas, tanto em um conjunto como em outro, as imagens orbitais foram incorporadas em grande quantidade e com objetivos diferentes. Na maioria das coleções dos livros didáticos de Geografia para o ensino fundamental e para o ensino médio, esse assunto tem ganhado certo destaque, compondo, junto da Cartografia, a temática vinculada às novas tecnologias. No entanto, o maior número de páginas com imagens de satélite está nos atlas geográficos.

Tal predomínio pode ser explicado, ainda que laconicamente, pelo fato de esse tipo de imagem ser disponibilizada "gratuitamente" por meio de várias plataformas virtuais, como Word Wind, Google Earth, Visual Earth, além dos sítios de institutos de pesquisa como o Instituto Nacional de Pesquisas Espaciais (INPE) e a Empresa Brasileira de Pesquisa Agropecuária (EMBRAPA), nos quais são disponibilizados esse tipo de linguagem, ao contrário das fotografias aéreas (verticais e oblíquas), cuja obtenção envolve os elevados custos aerofotogramétricos, conforme já mencionado. Esse tipo de fotografia pode ser obtido nos acervos analógicos 
ou digitais das secretarias municipais de planejamento urbano, das universidades ou de institutos de pesquisa.

Apresentaremos, na próxima seção, potências educativas a partir da utilização dos dois tipos de atlas supracitados e de fotografias aéreas verticais - em preto e branco (P\&B) - do município paulista de Rio Claro, com crianças entre 9 e 10 anos de idade, em escolas municipais, e o emprego de imagens provenientes da plataforma virtual Google Earth com estudantes da licenciatura em Ciências da EACH-USP.

Dos saberes espaciais e visuais cotidianos: experiências de ensino com escolares por meio das linguagens cartográfica e fotográfica do Sensoriamento Remoto

As experiências sobre o emprego de fotografias aéreas verticais e outras linguagens geográficas foram vivenciadas em duas escolas públicas do município paulista de Rio Claro: uma localizada na área central e outra situada na periferia da cidade, com turmas de Geografia da $4^{\mathrm{a}}$ série do ensino fundamental (atual $5^{\circ}$ ano), constituídas de 20 alunos cada uma, no final do ano 2000. O propósito da sequência didática foi proporcionar experiências com as professoras e os escolares empregando fotocópias de fotografias aéreas verticais de Rio Claro (em P\&B; escala gráfica de 1 por 5.000; datadas de junho de 1995), com excelente qualidade de impressão, a partir da escala geográfica de seus próprios corpos. Isso foi possível graças a nossa participação em duas fases do projeto temático Integrando universidade e escola por meio de uma pesquisa em colaboração: Atlas municipais escolares, financiado pela Fundação de Amparo à Pesquisa do Estado de São Paulo (FAFESP).

Apresentemos, então, cada uma das atividades.

$\mathrm{Na}$ primeira delas, realizamos uma caminhada ${ }^{7} \mathrm{com}$ as crianças pelo bairro onde a escola está localizada, porque a maior parte delas vivia ali, ficando, assim, mais fácil fazer com que elas confrontassem seus saberes corporais acerca do bairro onde vivem com os saberes fotográficos advindos da fotografia aérea vertical daquele mesmo bairro. Muitas crianças sentiram-se confusas ao confrontarem seus saberes corporais com as informações contidas na fotografia que cada uma tinha em mãos, porque foram apresentadas a uma "realidade" que, ao ser vista/olhada e vivida a partir do presente, deixou de ser um documento tão crível, afinal toda fotografia era datada, ou seja, apresentava informações num 
determinado momento histórico e, portanto, não era o espelho do real. Após a "caminhada educativa", várias atividades foram realizadas em sala de aula junto às crianças, empregando as mesmas fotografias aéreas verticais supracitadas. Relatamos, a seguir, por meio de excertos de aula, a continuidade dessa sequência didática.

Na segunda atividade, as crianças lançaram mão de uma planta urbana do bairro e mais a fotografia aérea vertical utilizada na "caminhada educativa", com a finalidade de comparar as linguagens cartográfica e fotográfica e descobrir tanto os limites como as potências educativas de cada uma delas. Um grupo de crianças afirmou: "o mapa é mais fácil, porque tem o nome das ruas e dos lugares". Perguntamos a elas se preferiam a fotografia ou o mapa. Um dos alunos respondeu: "No mapa eu tenho o nome das coisas e na foto não, mas um ajuda o outro, porque na foto é pior. É tudo pequenininho" ". Desse modo, as crianças, ao lerem o nome das ruas na planta urbana, transferindo-as para a fotografia aérea, forjaram passagens da experiência da "caminhada educativa" para a fotografia, evidenciando que aqueles mesmos nomes eram importantes em suas práticas espaciais e visuais cotidianas. E, por isso, a planta urbana era mais fácil, pois nela constavam referências utilizadas por eles em seus deslocamentos diários por aquele território. Houve também uma criança que sacou da mochila uma lupa para olhar a fotografia aérea. Estaria ela tentando descobrir formas conhecidas no dia a dia, mas que são difíceis de serem identificadas na fotografia aérea por serem demasiado pequenas, mesmo em uma escala detalhada? Com a lupa ampliando o que é visto, essas formas já conhecidas - uma esquina, uma praça, por exemplo saltariam aos seus olhos, facilitando uma espécie de abertura da fotografia e sua relação com o espaço vivido. Dúvidas que permaneceram, pois não perguntamos à aluna o que a levou a utilizar a lupa.

Em outro momento da atividade, a fotografia aérea solicitava, para seu entendimento e leitura, a relação entre parte e todo - típico conhecimento que pode ser melhor elaborado nas fotografias do que no cotidiano, pois nelas "vemos tudo ao mesmo tempo" - , conforme excerto.

Professora: Por que vocês utilizaram o mapa além da foto?

Aluno 1: Porque no mapa tem coisas escritas.

Professora: Qual a diferença entre o mapa e a foto?

Aluno 2: O mapa é desenhado e a foto não. A foto traz mais detalhes do que o mapa.

Professora: Que detalhes são esses? 
Aluno 3: O mapa só tem o contorno. Aqui na foto tem as casas e no mapa só tem o contorno dos quarteirões.

Professora: Os mapas são feitos como?

Aluno 2: Foto aérea. No mapa não dá pra ver as árvores. Na foto eu posso ver a arborização.

Professora: Qual rua é mais arborizada?

Aluno 4: A da Avenida da Saudade.

Outra passagem entre saberes corporais e fotográficos ocorreu quando uma das crianças disse que "a foto tá errada, porque não tem a peixaria e a chácara já não é mais daquele tamanho. Agora construíram casas e o tamanho da área ocupada pela chácara diminuiu”" ${ }^{10}$. Por meio dessa afirmação, foi possível notar a presença dos saberes corporais na leitura das fotografias, uma vez que foi a partir deles que a aluna questionou a veracidade da fotografia. Ela sabia que agora existia uma peixaria que não estava mais presente naquela fotografia. Passagens que revelaram a transformação no espaço onde se vive. Porém, o "dia em que essa aluna disser 'a foto é antiga, por isso tem coisas nela que são diferentes das de hoje', então teremos alcançado um outro tipo de conhecimento escolar" (Almeida et al., 2004, p. 54) menos maniqueísta, como relatou o aluno Vinicius: "Eu descobri que esta fotografia aérea é diferente do meu trajeto de casa à escola, porque esta fotografia é de 1995 e não mostra alguns pontos de referência que no meu trajeto diário tem"11.

Com as crianças da segunda escola, localizada na periferia da cidade e na fronteira entre os bairros Jardins Novo Wenzel, Bom Sucesso e Araucária, onde os alunos viviam, chamou a atenção delas, na fotografia aérea vertical, a presença somente de arruamentos, quarteirões e algumas construções. No entanto, as crianças ficaram impressionadas com o "olhar de cima” proporcionado pela fotografia. À época ainda não haviam sido criadas plataformas virtuais como Google Maps e Google Earth ${ }^{12}$, entre outras. O fato é que esse tipo de "vista do alto", proporcionado seja pelas imagens orbitais, seja pelas fotografias aéreas, ainda impressiona pessoas de todas as idades.

Na medida em que as crianças vão adensando conhecimentos e significados ao observarem a fotografia do bairro onde vivem, transportam para ela seus "saberes da experiência corporal já existentes" (Almeida et al., 2004, p.53), descobrindo ausências e permanências e, ao mesmo tempo, dando plasticidade àquela paisagem chapada, conforme o excerto: 
Aluno: Não tem nosso bairro aqui?

Professora: O bairro de vocês é muito novo e a fotografia é de 1995 $[\ldots]$

Aluno: Então, como a gente vai mapear a nossa casa se o Jardim Progresso não aparece nesta foto?

Professora: Observem que na fotografia aparece somente o loteamento. Então, vocês terão que dar existência mapeada ao bairro [...] Caren ${ }^{13}$, por exemplo, teve o mesmo problema, pois seu bairro - Jardim Araucária - também não existia na fotografia! ${ }^{14}$

Era preciso andar pelos bairros para reconhecer as mudanças em relação àquela fotografia aérea, pois os Jardins Novo Wenzel, Bom Sucesso e Araucária já não eram mais os mesmos. As crianças, assim, puseram-se a mapear o bairro e, para tanto, foram distribuídos a elas pedaços de acetato transparente para prenderem-no junto à fotografia. Foram elaborados 22 croquis e o bairro mapeado. Cada um dos croquis apresentava-se de modo muito diverso. Embora fossem croquis elaborados naquele momento, as grafias ali traçadas eram de um tempo situado no porvir daquelas crianças, repletas de desejos, reivindicações, angústias, medos e brincadeiras, conforme excerto do diálogo da professora às crianças.

Professora: Vocês lembram-se como estas fotografia foram feitas?

Alunos: É de 1995

Professora: Então, ela não é tão antiga.

Aluno 1: Eu tinha um ano e a professora já tinha quinze.

Professora: Esta foto está diferente em relação às coisas que vemos hoje nestes bairros próximos à escola?

Aluno 2: Não tinha o postinho.

Aluno 3: Na foto o bairro está mais bonito. Tem muito barraco lá perto de casa e isso deixa o bairro feio!

Professora: Você acha que se fosse casa normal ficaria melhor?O que você acha?

Aluno 3: Precisamos falar com o prefeito.

Professora: Vocês sabem que amanhã tem reunião sobre Orçamento Participativo. Ou seja, precisaremos pensar em um mapa para o Orçamento Participativo.

Professora: Por exemplo, tem a caixa d'água que não funciona mais no Jardim Novo Wenzel. A do Jardim Bom Sucesso funciona. 
Nesse processo de mapeamento, "mais que anotar ruas e avenidas no mapa, as histórias de vida contadas pelos alunos e pelos pais em reuniões ou em conversas informais eram recordadas" ${ }^{15}$. Nesse caso, é difícil apontar quais das linguagens solicitariam passagens pelos saberes corporais, fotográficos, cartográficos, entre outros, pois as circunstâncias espraiam-se para os contextos dos bairros adjacentes à escola, imiscuindo mapas e fotografias na compreensão daquelas geografias locais. As passagens pelos saberes corporais, solicitadas pelas fotografias aéreas e pelos croquis elaborados pelas crianças, fizeram com que a professora daquela turma ampliasse suas atividades junto às crianças para uma entrevista com um casal de antigos moradores que presidiam a Associação de Moradores dos Jardins Novo Wenzel e Bom Sucesso e que, dispostos, foram até a escola contar para os alunos sua história de vida que se cruzava com a história de todas os moradores daqueles bairros. Todos eram migrantes e, apesar de parecer que inexistiam ali, naquelas geografias periféricas, a tríade habitante-identidade-lugar estava sendo produzida e de forma imbricada com a história daqueles bairros que também era a história de cada morador que vivia ali (Carlos, 2007).

\section{Experiências de ensino com professoras e professores em formação: a plataforma} Google Earth

Nesta parte, apresentamos uma sequência didática constituída por quatro atividades desenvolvidas no contexto de uma disciplina ofertada para estudantes da licenciatura em Ciências da EACH-USP, objetivando apresentar e discutir a potência educativa das imagens geográficas na formação de professores. Na esteira do sociólogo português Boaventura de Sousa Santos (2000), citado neste texto, no item "Composição micropolítica”, a espacialidade é pertinente a todas as áreas do conhecimento e, por isso, cremos na importância de problematizarmos as linguagens cartográficas e as imagens orbitais, disponibilizadas sincronicamente pela plataforma Google Earth, em um curso de formação de professores de Ciências.

As três atividades da sequência didática foram desenvolvidas no laboratório de informática da universidade. Para a primeira atividade, adaptamos de Almeida, Sanchez e Picarelli (1996) o Quadro 1, com o propósito de explorar junto aos graduandos as diferenças existentes entre as linguagens da Cartografia e das imagens orbitais. Os mapas foram 
empregados junto das imagens orbitais para explorar as potencialidades e os limites educativos de cada um dessas linguagens.

\begin{tabular}{|c|l|l|}
\cline { 2 - 4 } \multicolumn{1}{c|}{} & O que você vê & \multicolumn{1}{|c|}{ O que você não vê } \\
\hline Imagens orbitais & $\begin{array}{l}\text { Tudo o que foi enquadrado a partir de } \\
\text { determinada resolução espacial na qual } \\
\text { a imagem orbital foi obtida. A imagem, } \\
\text { embora chape as rugosidades dos } \\
\text { lugares, é mais familiar por ser parecida } \\
\text { com os aspectos vistos e vividos nos } \\
\text { deslocamentos diários que realizamos } \\
\text { pela cidade. }\end{array}$ & $\begin{array}{l}\text { nome das coisas, no entanto a rede } \\
\text { hidrográfica urbana canalizada continua } \\
\text { invisível, pois está sob o asfalto. Percebe- } \\
\text { se existência dos rios em decorrência } \\
\text { do cheiro que deles exala, invisível nas } \\
\text { imagens. }\end{array}$ \\
\hline Mapas & $\begin{array}{l}\text { Aqui as informações estão sempre } \\
\text { representadas de forma seletiva. } \\
\text { Se a escala for grande, haverá mais } \\
\text { detalhes das informações mapeadas; } \\
\text { se, ao contrário, a escala for pequena, } \\
\text { haverá generalização das informações } \\
\text { mapeadas. }\end{array}$ & $\begin{array}{l}\text { Como o espaço foi reduzido à segunda } \\
\text { dimensão, ele se tornou algo possível de ser } \\
\text { imaginado como uma superfície horizontal. } \\
\text { E, ao contrário da imagem orbital, aqui não } \\
\text { é possível ver as coisas e as formas com as } \\
\text { quais nossos olhos estão acostumados. }\end{array}$ \\
\hline
\end{tabular}

Quadro 1 - Escala cartográfica: entre detalhamentos e generalizações.

Fonte: Adaptação de Almeida, Sanchez e Picarelli (1996, p.11).

Na plataforma Google Earth, há a possibilidade de ver um dado lugar, seja por meio das imagens orbitais, seja por meio de mapas; ver, porque todas as rugosidades da superfície terrestre são chapadas em ambas as linguagens, em decorrência de o ponto de vista vertical assumido nos mapas ser semelhante ao das imagens orbitais. Interessante destacar que, naquela plataforma, a imagem orbital não é apresentada em detrimento do mapa. Pelo contrário, uma linguagem mais polissêmica e menos codificada, como a imagem orbital, compõe a plataforma com os mapas, linguagem codificada. Há algum tempo, a plataforma também incorporou a ferramenta Street View, por meio da qual é possível conhecer fotograficamente, no nível do solo, vários locais da Terra. Mas há que tomar certo cuidado com os estereótipos imagéticos. Consideremos a coleção Amazonas[16] que, ao adensar e homogeneizar fotograficamente um estado tão diverso e complexo, o faz por meio de 28 fotografias apresentando, portanto, somente três rios (Negro, Mariepauá e Aripuanã) dentre a ampla rede hidrográfica amazonense, pequenos trechos da extensiva floresta, 
algumas comunidades locais (Tumbira, Santa Helena e Saracá), e uma trilha situada em suposta área de reflorestamento. Perguntamos então: será que essas fotografias apresentariam a complexidade da área? Além disso, o título da coleção referir-se-ia a uma das 27 unidades federativas do Brasil ou somente ao rio de nome homônimo ao estado do Amazonas? Essas imagens não produziriam um imaginário coletivo estereotipado no que diz respeito à sociobiodiversidade dessa área?

A segunda atividade consistiu na apresentação do conceito de região, estado e município a partir das Figuras 3, 4, 5, e 6, extraídas da plataforma Google Earth.

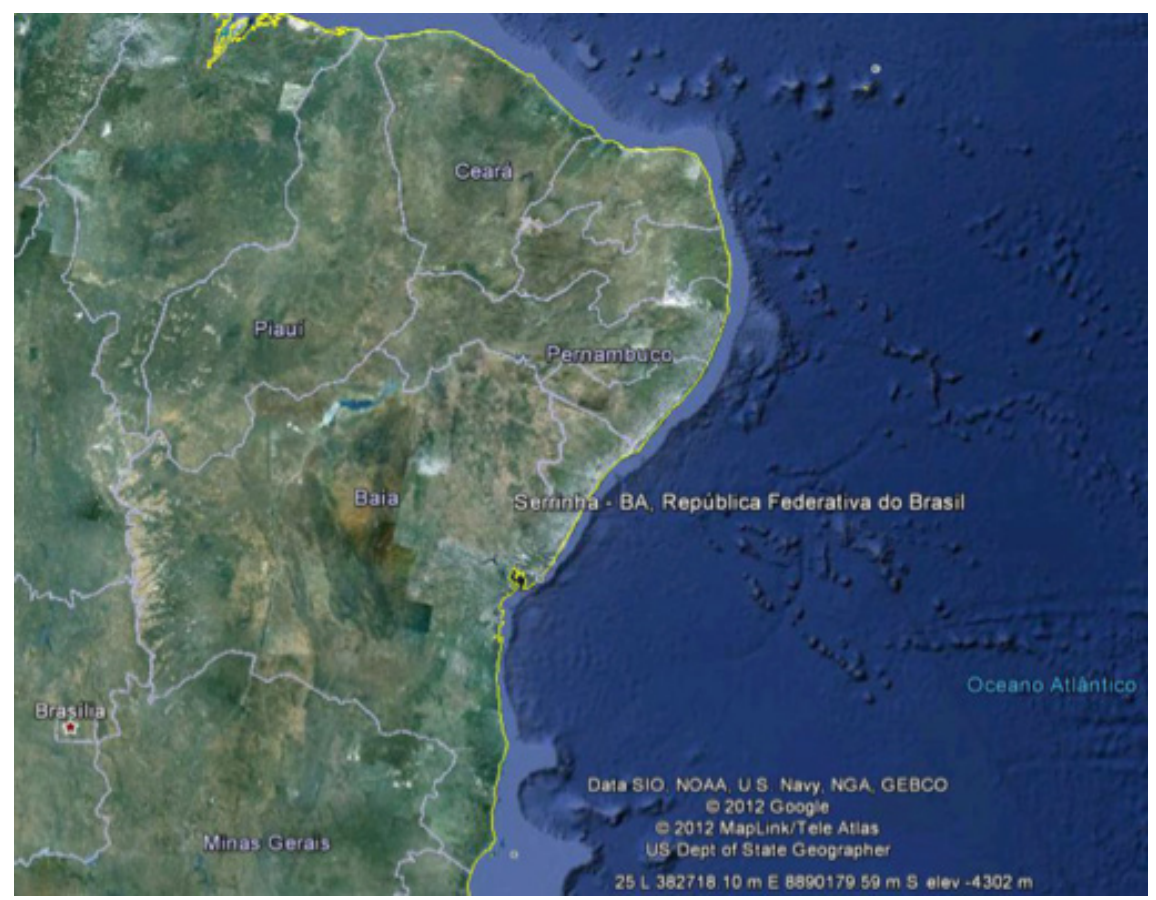

Figura 3 - Imagem orbital e os estados da região Nordeste.

Fonte: Plataforma Google Earth. Acesso em: 26 mar. 2013. 


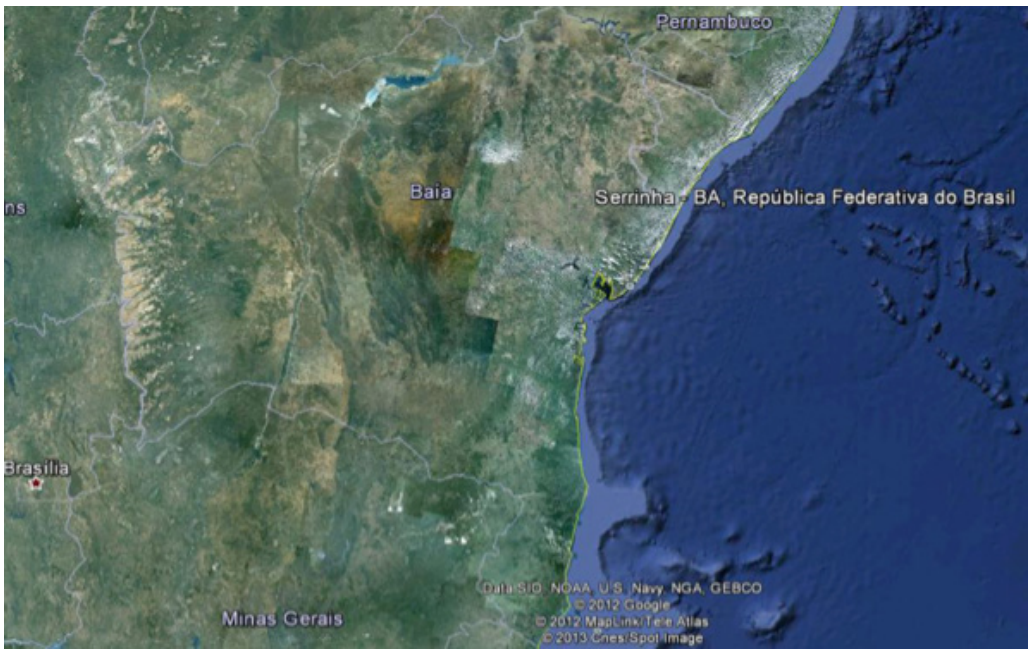

Figura 4 - Imagem orbital com a localização do município de Serrinha, no estado da Bahia.

Fonte: Plataforma Google Earth. Acesso em: 26 mar. 2013.

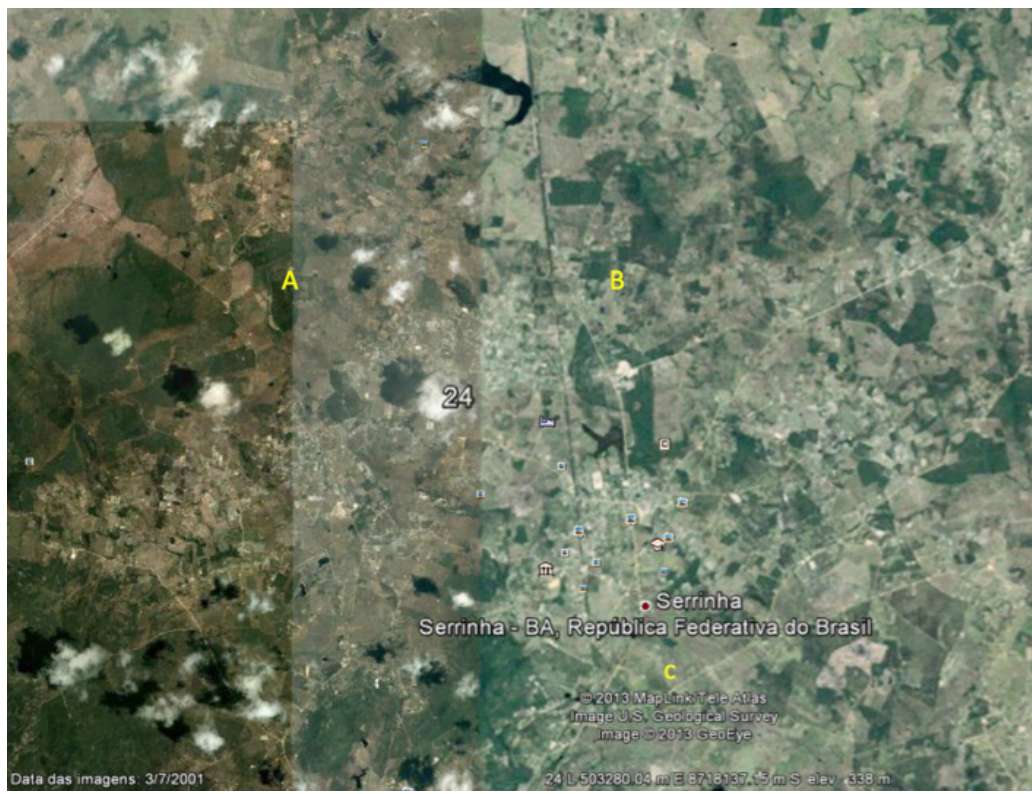

Figura 5 - Mosaico fotográfico e imagético.

Fonte: Plataforma Google Earth. Acesso em: 26 mar. 2013. 


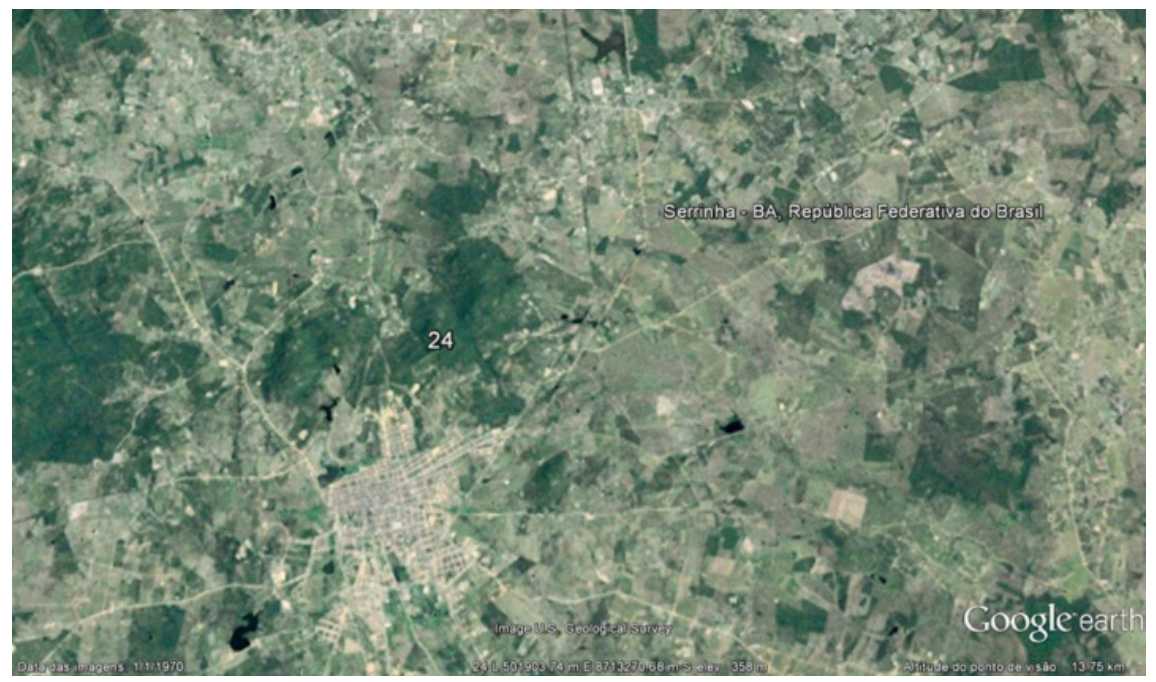

Figura 6 - Imagem orbital do município de Serrinha (BA).

Fonte: Plataforma Google Earth. Acesso em: 26 mar. 2013.

Na Figura 3, destacamos os nove estados que compõem a região Nordeste; na Figura 4, chamamos a atenção para a localização de Serrinha no estado da Bahia; na Figura 5, municípios adjacentes à Serrinha (círculo vermelho no centro da imagem, na parte inferior) são apresentados por meio de um mosaico imagético, montado a partir de imagens orbitais e fotografias aéreas verticais coloridas e em P\&B obtidas em épocas diferentes. Por fim, na Figura 6, o município de Serrinha é apresentado em uma escala mais detalhada, porém a imagem não está nítida.

Retornemos à Figura 5. Ao observá-la, é possível detectar a data das imagens. Cada uma das duas marcações (A e B) que fizemos na Figura 5 corresponde a datas diferentes de obtenção. O trecho " $\mathrm{A}$ " foi obtido em $3 / 07 / 2001^{17}$ e corresponde à imagem orbital; e o trecho "B", em 1/1/1970, correspondendo a uma fotografia aérea vertical. Ainda nessa imagem é possível ler: “@2013 Map link/Teleatlas; Image U.S. Geological Survey; Image@2013 Geo Eye”. Ou seja, as imagens que compõem o mosaico da plataforma Google Earth não são realizadas em “tempo real” e "por mais recentes que sejam os dados, o sonho de se ter uma 'câmera' filmando tudo do espaço continua sendo isso mesmo, um sonho” (Oliveira, 2007, p.49). 
A finalidade de apresentar as Figuras 3, 4, 5 e 6 foi desnaturalizar, junto aos estudantes de licenciatura em Ciências, conceitos como região, estado e município, perspectivados desde a Cartografia simbólica por meio dos três mecanismos cartográficos de produção da realidade: escala, projeção e simbologia (Santos, 2000; Cazetta, 2005; Seemann, 2005), pois "tão importante como saber que as coisas mudam com o tamanho, é saber exatamente o que muda e como" (Castro, 2003, p.121). A escala corresponde a uma estratégia de aproximação do real, incluindo

[...] tanto a inseparabilidade entre tamanho e fenômeno, o que a define como problema dimensional, como a complexidade dos fenômenos e a impossibilidade de apreendê-los diretamente, o que a coloca como um problema também fenomenal (Castro, 2003, p. 118).

As projeções cartográficas, por sua vez, criam visões de mundo. Os cartógrafos, ao transferirem informações da esfera terrestre para o plano bidimensional, criam, inevitavelmente, distorções ${ }^{18}$ no mapa, porque este sempre estará centrado em um determinado ponto, criando centros e periferias (Seemann, 2005). A simbologia, por sua vez, pode ser de dois tipos: uma baseada na "gramática cartográfica" e a outra ancorada na subjetividade, "vinculada às percepções e sentidos atribuídos pelas pessoas a essa linguagem supostamente objetiva que é a representação gráfica” (Cazetta, 2005, p. 64-65). A primeira é condicionada pela escala, projeção e simbologia; e a segunda problematiza as generalizações produzidas no interior das convenções cartográficas.

No Quadro 2, extraído de Seemann (2005), é possível ter uma ideia de como abordamos os três mecanismos cartográficos aplicadas à leitura das Figuras 3, 4, 5 e 6, bem como das imagens dos despretensiosos livros de Istvan Banyai (1995a, 1995b), intitulados Zoom e Re-Zoom.

\begin{tabular}{|c|c|c|c|}
\hline $\begin{array}{l}\text { Agente produtor } e \\
\text { consumidor }\end{array}$ & Escala & Projeção & Simbologia \\
\hline $\begin{array}{l}\text { Proprietários dos meios } \\
\text { de produção e industriais }\end{array}$ & $\begin{array}{c}\text { Escala média e grande } \\
\text { - Interesse pela } \\
\text { infraestrutura } \\
\text { - Redes e fluxos } \\
\text { - Produção em vez de } \\
\text { população }\end{array}$ & $\begin{array}{c}\text { Centrado no processo de } \\
\text { produção } \\
\text { - Relações com o mercado } \\
\text { (verticalidades) } \\
\text { - Imagem seletiva da realidade } \\
\text { visando ao lucro da empresa }\end{array}$ & $\begin{array}{c}\text { Discurso de realce } \\
\text { - Transmissão de uma } \\
\text { imagem positiva da } \\
\text { empresa } \\
\text { - Incentivo à produção } \\
\text { e ao consumo } \\
\text { (propaganda) }\end{array}$ \\
\hline
\end{tabular}




\begin{tabular}{|c|c|c|c|}
\hline Promotores imobiliários & $\begin{array}{c}\text { Escala grande } \\
\text { - Interesse pelos imóveis } \\
\text { - Capital em vez de } \\
\text { valores humanos } \\
\text { - Especulação }\end{array}$ & $\begin{array}{l}\text { Centrado nos imóveis } \\
\text { - Apenas um mapeamento } \\
\text { do que interessa: casas, } \\
\text { apartamentos, terrenos; } \\
\text { qualidade de vida; vizinhança; } \\
\text { valor dos imóveis e o possível } \\
\text { lucro }\end{array}$ & $\begin{array}{c}\text { Discurso persuasivo } \\
\text { - Apresentação de todas } \\
\text { as vantagens na compra } \\
\text { do imóvel } \\
\text { - Localidade, } \\
\text { infraestrutura, preço etc. }\end{array}$ \\
\hline Estado / prefeitura & $\begin{array}{l}\text { Escala pequena e } \\
\text { média } \\
\text { - Generalização: reduz } \\
\text { o comportamento e as } \\
\text { atitudes a tipos gerais } \\
\text { de dados abstratos e } \\
\text { de estatísticas } \\
\text { - Discurso político } \\
\text { - Planejamento urbano }\end{array}$ & $\begin{array}{c}\text { Centrado na cidade } \\
\text { inteira } \\
\text { - Criação de espaços } \\
\text { privilegiados e marginalizados, } \\
\text { segregação } \\
\text { - Planejamento urbano } \\
\text { - Discurso de desenvolvimento } \\
\text { - Embelezamento da realidade: } \\
\text { propaganda pelos cartões- } \\
\text { postais da cidade } \\
\text { - Omissão ou redução da } \\
\text { periferia }\end{array}$ & $\begin{array}{l}\text { Discurso político } \\
\text { - Plano diretor, } \\
\text { levantamentos, } \\
\text { relatórios, legislação } \\
\text { - Assistencialismo/ } \\
\text { voluntarismo } \\
\text { - Tensão: discurso x } \\
\text { ação }\end{array}$ \\
\hline Grupos sociais excluídos & $\begin{array}{c}\text { Escala muito grande } \\
\text { - Espaço vivido, } \\
\text { vizinhança, casa, rua, } \\
\text { bairro } \\
\text { - Percepção de detalhes } \\
\text { importantes para o } \\
\text { grupo ou os indivíduos; } \\
\text { microterritorialização }\end{array}$ & $\begin{array}{c}\text { Centrado na periferia } \\
\text { - Acatamento do discurso } \\
\text { político que define a periferia } \\
\text { - Projetos pessoais e } \\
\text { comunitários }\end{array}$ & $\begin{array}{l}\text { Discurso militante } \\
\text { - Movimentos sociais, } \\
\text { associações de } \\
\text { moradores, parcerias } \\
\text { com ONGs } \\
\text { - Articulação com os } \\
\text { outros agentes }\end{array}$ \\
\hline
\end{tabular}

Quadro 2 - Agentes produtores e consumidores conforme as suas escalas, projeções e simbologias.

Fonte: Seemann $(2005$, p.13967).

Além da discussão geográfica acerca da região, foi possível abordar a contribuição de outros teóricos, como o historiador Durval Muniz de Albuquerque Júnior (2011), para quem a região geográfica Nordeste não existia até meados da década de 1910. Esse autor pensa o Nordeste “[...] como uma identidade especial, construída em um preciso momento histórico, final da primeira década do século passado e na segunda década, como produto do entrecruzamento de práticas e discursos 'regionalistas"' (Albuquerque Júnior, 2011, p.33). Essa proposta encaixa-se bem para o propósito que tivemos neste texto. Ou seja, ao mesmo tempo em que apresentamos potencialidades educativas de apreensão de temas geográficos específicos, procuramos ampliá-los com leituras feitas fora do âmbito geográfico, pois é necessário romper "com as transparências 
dos espaços e das linguagens” (Albuquerque Júnior, 2011, p. 33), as quais, geralmente, apresentam o espaço geográfico como "uma superfície plana, uma superfície contínua. O espaço como produto acabado. Como um sistema coerente" (Massey, 2008, p. 159).

A terceira e última atividade consistiu numa "caminhada educativa" pelo campus da universidade, com a finalidade de comparar a imagem extraída da plataforma virtual Google Earth com as saberes corporais que os licenciados adquiriram dos deslocamentos realizados frequentemente no campus, afinal, as imagens orbitais foram obtidas a "partir do real", não constituindo a realidade em si. Outrossim, as imagens eram datadas. Esses dois aspectos interpelativos provocaram os estudantes a olhar para as imagens em relação a outras linguagens, como os mapas, a partir da cartografia simbólica e seus elementos de escala, projeção e simbologia. Isso possibilitou uma espécie de desmontagem das imagens orbitais, remontadas a partir dos mapas e dos saberes espaciais e corporais dos estudantes.

\section{Considerações finais}

No presente texto, argumentamos desde a micropolítica até o cruzamento da oposição micro e macroescala, pois a corporeidade, em conexão inevitável com os espaços, suplanta qualquer oposição desse tipo. Consideramos o conjunto dos mapas e das imagens do Sensoriamento Remoto, grosso modo, como imagens; generalizamos sabendo que cada uma delas obedece a um processo de produção distinto e, portanto, a uma política estética também variada. Tal problematização ficou mais bem evidenciada quando foram apresentados os resultados de pesquisa nas ambiências escolar e universitária, ao empregarmos ambos os tipos de linguagens. A primeira, operada com mapas e fotografias aéreas verticais em $\mathrm{P} \& \mathrm{~B}$, e a segunda, a partir da cartografia simbólica desde os elementos de escala, projeção e simbologia, empregados para pensar o espaço e suas rugosidades e as corporeidades.

Portanto, esse modo de pensar pode desmontar e potencializar outras remontagens das linguagens inventadas por nós na instituição de reais, tendo no pensamento multiescalar, nos diferentes pontos de vista e na proliferação de simbologias o procedimento para desnaturalizar narrativas que almejam homogeneizar um modo de vida único, como caminho inevitável de processos históricos que, ao invés de lineares e 
universalizantes, são incomuns e contingentes. Para tanto, basta escavar as inúmeras camadas acontecimentais das geografias ordinárias e oficiais, como aquelas apontadas pelas crianças que vivem sincronicamente na periferia e no centro das decisões micropolíticas.

\section{Notas}

10 filósofo, historiador e crítico de arte francês Georges Didi-Huberman (2017, p.28) diz que as coisas chãs são as primeiras "a serem vistas", ou seja, são aquelas "que temos 'debaixo do nariz'".

2 Para mais informações ver: <http://www5.each.usp.br/licenciatura-em-ciencias-danatureza/>. Acesso em: 5 abr. 2018.

3 Marisa Monte fala sobre show em escola ocupada: 'Só existe amor na micropolítica'". Extra Digital, Rio de Janeiro, 5 mai. 2016. Disponível em: <https://extra.globo.com/ famosos/marisa-monte-fala-sobre-show-em-escola-ocupada-so-existe-amor-namicropolitica-19233989.html> Acesso em: 5 abr. 2018.

4 Notícia disponível em: <https://extra.globo.com/famosos/marisa-monte-fala-sobreshow-em-escola-ocupada-so-existe-amor-na-micropolitica-19233989.html> Acesso em: 5 abr. 2018.

5 Termo cunhado no começo dos anos de 1960, quando a fotografia aérea era o principal sensor remoto.

6 No caso das imagens orbitais, o termo mais adequado a ser empregado é "resolução espacial" ao invés de "escala" - conceito aplicado aos produtos cartográficos. Para Assis (2001, p.12), "a resolução espacial seria para o Sensoriamento Remoto o que a escala gráfica é para a aerofotogrametria e para a Cartografia".

7 Consiste na capacidade do sensor em detectar as variações de radiação provindas do espectro eletromagnético. No caso dos sistemas fotográficos, a resolução radiométrica do sensor é indicada pelos níveis de cinza reconhecidos pelo filme fotográfico. No caso dos sensores ópticos eletrônicos a bordo dos satélites artificiais, a imagem apresentarse-á necessariamente em formato digital (numérica), porque, nesse caso, a resolução radiométrica somente será identificada na faixa de valores codificada pelo sensor (Chuvieco, 1996).

8 Foram necessárias para essa atividade duas aulas de 50 minutos. Um dos inspetores da escola acompanhou as duas turmas, organizadas em dias alternados, para realizar a "caminhada educativa".

9 Notas de caderno de campo do dia 31/10/2003.

10 Notas de caderno de campo do dia 31/10/2003.

11 Notas de caderno de campo do dia 13/11/2003.

12 Notas de caderno de campo do dia 13/11/2003.

$13 \mathrm{O}$ aplicativo Google Earth - concebido inicialmente pela Keyhole com o nome de Earth Viewer - foi adquirido e disponibilizado "gratuitamente" pelo Google, em junho de 
2005 , com a finalidade de comercializar imagens orbitais. No entanto, sua popularização desencadeou outros usos dados pela sociedade civil e, dentre eles, vale mencionar o emprego feito pelos artistas. Para maiores detalhes ver a pesquisa de Leirias (2012).

14 Nome fictício atribuído aos sujeitos da pesquisa.

15 Notas de caderno de campo do dia 23/05/2003.

16 Narrativa de uma das professoras referente ao segundo semestre de 2003.

17 Disponível em: <https://www.google.com.br/intl/pt/streetview/\#amazon>. Acesso em: 10 jan. 2018.

18 Nas imagens da plataforma Google Earth, segue-se o modelo americano de datação, ou seja, primeiramente é grafado o mês, seguido do dia, e, por fim, o ano (month/day/ year).

19 Podemos citar o exemplo clássico da projeção cilíndrica de Mercator, na qual a Groenlândia parece ter o tamanho do Brasil, mas é quatro vezes menor.

\section{Referências}

ALBUQUERQUE JÚNIOR, D. M. A invenção do Nordeste e outras artes. 5. ed. São Paulo: Cortez, 2011.

ALMEIDA, R. D. de; BONOTTO, D.; TENCA; Á.; OLIVEIRA JUNIOR, W. M. de; KAHLIL, S. P. Integrando universidade e escola por meio de uma pesquisa em colaboração: atlas municipais escolares. São Paulo: FAPESP/Programa Ensino Público, 2004. (Relatório Final de Pesquisa)

ALMEIDA, R. D.; SANCHEZ, M. C.; PICARELLI, A. Atividades cartográficas. São Paulo: Atual, 1996. (v. 4).

ASSIS, R. R. de. Utilização de imagens orbitais e aéreas no estudo da ocupação e planejamento urbano. 2001. 35 f. Monografia (Especialização) - Departamento de Geografia, Universidade Federal de Minas Gerais, 2001. Disponível em: <http://www.csr.ufmg.br/geoprocessamento/publicacoes/rochaassis2000.pdf>. Acesso em: 15 jan. 2013.

BANYAI, I. Zoom. New York: Puffin, 1995a.

. Re-Zoom. New York: Puffin, 1995b.

CAMPOS, D. Q. Um saber montado: Georges Didi-Huberman a montar imagem e tempo. Aniki: Revista Portuguesa da Imagem em Movimento, América do Norte, 4, maio. 2017. Disponível em: <http://aim.org.pt/ojs/index.php/revista/article/ view/299>. Acesso em: 19 abr. 2018.

CARLOS, A. F. A. O lugar no/do mundo. São Paulo: Labur Edições/GESP, 2007.

CASTRO, I. E. de. O problema da escala. In: CASTRO, I. E. de; GOMES, P. C. C.; CÔRREA, R. L. (Org.). Geografia: conceitos e temas. 5. ed. Rio de Janeiro: Bertrand Brasil, 2003. p. 117-140. 
CAZETTA, V. Práticas educativas, processos de mapeamento e fotografias aéreas verticais: passagens e constituição de saberes. 2005. 189 f. Tese (Doutorado em Geografia) - Instituto de Geociências e Ciências Exatas, Universidade Estadual Paulista, Rio Claro, 2005.

. Educação visual do espaço e o Google Earth. In: ALMEIDA, R. (Org.).

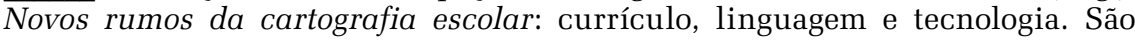
Paulo: Contexto, 2011. p. 177-186. (v. 2).

. A visualidade dos atlas geográficos escolares brasileiros e a ideologia

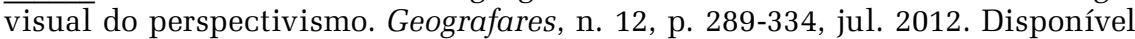
em: <http://periodicos.ufes.br/geografares/article/view/3196>. Acesso em: 27 mar. 2013.

CHUVIECO, E. Fundamentos de teledetección espacial. 3. ed. Madrid: Rialp, 1996.

DIDI-HUBERMAN, G. Cascas. Tradução de André Telles. São Paulo: Editora 34, 2017.

FERREIRA, P. F. M.; MATIAS, L. F. Geotecnologias: potencialidades e riscos. Revista Geográfica de América Central, Costa Rica, v. 2, n. 47, p. 1-14, 2011.

FLORENZANO, T. G. Geotecnologias na Geografia aplicada: difusão e acesso. Revista do Departamento de Geografia, n. 17, p. 24-29, 2005. Disponível em: $<$ http://www.Geografia.fflch.usp.br/publicacoes/RDG/RDG_17/Teresa_Gallotti_ Florenzano.pdf>. Acesso em: 20 jan. 2013.

GUATTARI, F.; ROLNIK, S. Micropolítica: cartografias do desejo. 12a Ed. Petrópolis: Vozes, 2013.

LEIRIAS, A. G. Novas cartografias on line, arte contemporânea e outras Geografias. Geograficidade, Niterói, n. 2, p. 115-133, 2012. Disponível em: $<$ http://www.uff.br/posarq/geograficidade/revista/index.php/geograficidade/ article/view/59>. Acesso em: 28 mar. 2013.

MARISA Monte fala sobre show em escola ocupada: 'Só existe amor na micropolítica”'. Extra Digital, Rio de Janeiro, 5 mai. 2016. Disponível em: < https:// extra.globo.com/famosos/marisa-monte-fala-sobre-show-em-escola-ocupada-soexiste-amor-na-micropolitica-19233989.html> Acesso em: 5 abr. 2018.

MASSEY, D. Pelo espaço: uma nova política da espacialidade. Tradução: Hilda Pareto Maciel e Rogério Haesbaert. Rio de Janeiro: Bertrand Brasil, 2008.

MATIAS, L. F. Por uma economia política das geotecnologias. In: ENCONTRO DE GEÓGRAFOS DA AMÉRICA LATINA, 10., 2005, São Paulo. Anais... São Paulo: Universidade de São Paulo, 2005. p. 8879-8899.

OLIVEIRA, Eduardo Freitas. Por trás das imagens. InfoGPS, Curitiba, n. 3, p.4951, nov./dez. 2007.

OLIVEIRA JÚNIOR, W. M. de. Fotografias e conhecimentos do lugar onde se vive - linguagem fotográfica e atlas municipais escolares. In: ALMEIDA, R. D. de A. (Org.). Novos rumos da cartografia escolar. São Paulo: Contexto, 2011. p. 13-36. 
SANTOS, B. de S. A crítica da razão indolente: contra o desperdício da experiência. São Paulo: Cortez, 2000.

SANTOS, Milton. A natureza do Espaço: espaço e tempo, razão e emoção. São Paulo: Hucitec, 1997.

SEEMANN, J. Metáforas espaciais na Geografia: cartografias, mapas e mapeamentos. In: ENCONTRO DE GEÓGRAFOS DA AMÉRICA LATINA, 10., 2005, São Paulo. Anais... São Paulo: Universidade de São Paulo, 2005. p. $13955-13971$.

Valéria Cazetta - Licenciada em Geografia pela Universidade Estadual Paulista, com mestrado e doutorado pela mesma instituição. Atualmente é professora na Escola de Artes, Ciências e Humanidades da Universidade de São Paulo. ORCID: https://orcid.org/0000-0001-5921-6074

Recebido para publicação em 27 de março de 2018 Aceito para publicação em 25 de abril de 2018 